\title{
Los pájaros se han ido
}

\section{Israel Nicasio-Álvarez}

«iPuedes traer un poco de alcohol?», le digo a Emmanuel con insistencia, sé que no me ha escuchado. El dolor me aturde; intento controlarme, pero con cada segundo llega una punzada que bloquea mis pensamientos. «iDespierta! ¿Puedes ir por un poco de alcohol? Me sangra el brazo», repito casi gritándole. «Sí, tío, ya voy», responde. Corre escaleras abajo. Miro a la abuela, ella también me mira, tiene miedo. Es como si en algún momento le hubiera dicho que le haría daño y ella solo hubiera reaccionado para defenderse, me mordió con tanta fuerza que apenas puedo pensar claramente. Escucho el cantar de los pájaros en el patio. Ese sonido contrasta con el dolor que me envuelve el brazo. Ojalá logremos tranquilizar a la abuela para que pueda dormir hoy, pienso.

Emmanuel regresa después de algunos minutos. Trae consigo el bote de alcohol casi vacío, seguramente lo encontró en el anaquel del baño; apenas lo puede manipular, pero tiene la mirada fija en una sola cosa: mi brazo. Conoce de memoria cada parte de esta casa, la ha recorrido centímetro a centímetro. Su juego favorito, aquel donde escondo objetos y él los busca, lo ha hecho el mejor geógrafo en este universo de concreto.

«iMe ayudas?», le pregunto. Asiente moviendo la cabeza. No deja de mirar mi brazo, por momentos mira a la abuela. «Vas a poner un poco de alcohol aquí y después vas a limpiar con este algodón la herida», le digo. Apesar de hablar muy poco, sé que me ha entendido, su mirada atenta lo confirma todo. Siempre ha sido un niño extraño. Para Emmanuel es difícil concentrarse, pero cuando lo logra no hay detalle que pueda olvidar. Sabe de memoria las arrugas de la abuela, conoce la totalidad de su cara cetrina. 
Estiro el brazo, Emmanuel vierte con cuidado el líquido, se detiene al mirar el dolor en mi cara. Casi no puedo controlarme. Pido que continúe, aunque el sufrimiento es insoportable. Después toma el algodón, lo acerca a mi piel. Su tacto es el de un cirujano; frunce el ceño, se concentra, mira detenidamente la herida y limpia con parsimonia. «iTe duele, tío?», me pregunta como si compartiera esa sensación que me consume. Apretando la mandíbula lo más que puedo y tratando de no respirar, le digo que sí. Procuro pensar en el canto de los pájaros, quiero que me calmen el dolor por un momento.

La abuela nos mira. Espera sentada. No habla. Tampoco quiere compañía, pero debe comer. No es sencillo para ella lidiar con los desconocidos de hoy. Poco a poco nos ha ido dejando en la oscuridad de su memoria. Lo sé porque, a pesar de que mi cara ha permanecido igual por muchos años, no me reconoce. Me duele saber de su olvido. La cara de Emmanuel sí ha cambiado. Solo su mirada se mantiene, es la misma que la de la abuela. No sé si acercarme y ofrecerle comida otra vez o esperar a que ella tenga más hambre para que se aproxime por su cuenta. Me siento ansioso.

«Abuela, ¿Tienes hambre? Ya es tarde ¿Quieres un pan? Hay leche. iMira, traje algo para leer contigo!», dice Emmanuel, mientras levanta un libro del piso. Yo reviso la herida que me ha dejado el reciente ataque; no es profunda, pero sí muy dolorosa. El flujo de la sangre se ha reducido un poco.

Emmanuel sigue hablado. Ella escucha, no responde. Está confundida. Lo noto porque su mirada va de un lado a otro. Intenta decir algo que se pierde en la punta de su lengua. Nos mira con atención. Mi sobrino hace pocas preguntas, sabe lo compleja que se ha vuelto esta visita. Es fuerte. Se sienta a un lado de la abuela, sostiene el libro con cierta dificultad. Antes de empezar a leer le explica un poco la historia de ese enorme tabique colorido. De tanto subir y bajar con él a cuestas las pastas ya empiezan a dar muestras del desgaste, en la portada hay un barco pirata.

La abuela nos mira. Mira al niño que se ha sentado a un costado suyo y mira al hombre que le pide, con los ojos, un poco de calma. Por un momento todo se detiene. Mientras Emmanuel habla sobre el barco, me doy cuenta de que ella por fin lo identifica. Lo acaricia y él dibuja una sonrisa tan grande como para iluminar este lugar. Todos sonreímos. Ella también me reconoce, mira mi barba larga y dice que debería recortarla. Me pregunta si ya comimos porque tiene hambre. Le doy un pedazo de pan. Emmanuel sale del cuarto a toda velocidad. Lo escucho correr.

Recuerdo cuando conocí al niño que ahora me acompaña. Apenas pude verlo entre un montón de cobijas. Era diciembre, el frío hacía doler los huesos. Lo saludé como si hubiera pasado algunas décadas sin verlo, como si lo hubiera conocido en un pasado muy lejano. Seguramente él ni notó mi presencia, pero desde ese momento le prometí jamás dejarlo solo. 
La abuela mira mi brazo, los ojos casi se le salen al ver la herida. «¿Qué te pasó?», me pregunta. No sé qué responder. Intento desviar la atención y camino un poco. Me pide tener más cuidado. "No te preocupes, abue, fue un accidente. Voy a estar bien», respondo. Ella sonríe con toda la fuerza que le puede dar el saberse en un lugar conocido. Me gustaría guardar ese momento, ayudarla a recordar todo; quisiera cuidarla hasta que deje de olvidar.

Emmanuel regresa a la recámara con un vaso entre las manos. Llena el recipiente con leche y se lo entrega a la abuela, le acaricia las manos como deseando no soltarla. Me regala una sonrisa, le contesto con el mismo gesto, lo hago lo mejor que puedo. Tengo el corazón roto. Él no debe saberlo, lo más probable es que el suyo también esté hecho pedazos, pero es valiente y sonríe.

«Te quiero mucho, abuela», dice Emmanuel, mientras ella mastica el pan. «No olvides que te quiero mucho», repite. La abuela nos dice que también nos quiere, me pide darle una fotografía localizada sobre su tocador. Señala la que tiene un marco sencillo de madera, en la imagen ella carga a un bebé envuelto en cobijas. «De seguro era uno de los dos, se parecían mucho», nos dice la abuela.

El sonido de los pájaros alivia la tensa calma que hay aquí. ¿Alguno debería decir algo?, me pregunto. La abuela mira el espejo con temor, tal vez empieza a no saber quién está del otro lado. Se acomoda sobre la mecedora. Por un momento me sentí feliz. El dolor en el brazo me recuerda lo fugaz de ese sentimiento, ambos deben ser pasajeros. No se quedará aquí para siempre, lo sé. Ahora ella mira a través del ventanal de la recámara. Su mirada se empieza a perder entre los colores del jardín que por años cuidó.

Recuerdo las visitas a esta casa con mucha nostalgia. El jardín con la fuente, que solo una vez tuvo agua, era maravilloso. De pequeños, todos los primos nos reuníamos para jugar, reíamos hasta caer rendidos mirando al cielo, hablábamos de lo mucho que deseábamos no crecer. Yo amaba acercarme a las jaulas de los pájaros que mi abuela cuidaba. Los escuchaba cantar y no sabía si lo hacían por desesperación o por saberse a salvo de un posible depredador. Me encantaba verlos tan cercanos, tan pequeños, pero me dolía su encierro. Tal vez rogaban por su libertad. La abuela los alimentaba con mucha devoción. También les hablaba, supongo que les contaba sobre su vida y su soledad, ellos sabían su nombre real: Teresa. No se llamaba abuela, así le decíamos como muestra de cariño.

Cuando ella empieza a cerrar los ojos, entiendo que es momento de cambiarla de lugar, la mecedora no la dejará descansar por completo. Emmanuel me ayuda a recostarla sobre la cama. Hago lo que puedo para moverla sin causarle alguna incomodidad, aunque eso me es casi imposible: el dolor en mi brazo entorpece la maniobra. Teresa abre los ojos. Su mirada nos desconoce. Se aferra a mí como esperando 
la respuesta de alguna pregunta que no conozco. Tal vez quiere saber quién soy. Tal vez quiere saber quién es ella. Estando en la cama, la abuela se acurruca, se encierra en sí misma, se mete a su caparazón. Con una mirada dubitativa recorre todo el lugar. Antes de cubrirla por completo, para salvarla del frío, la miro. Veo el blanco de sus cabellos, sus mejillas arrugadas, veo los nudos de sus manos. No suelta la fotografía que le entregué, pienso que esa imagen es como el hilo que guió a Teseo a través del oscuro laberinto. Tengo miedo de perderla otra vez.

Emmanuel no hace preguntas, sus ojos a punto de reventar me dicen que necesita a su abuela de vuelta. Le alboroto el cabello para distraerlo. Lo abrazo. Escucho los pájaros cantando. «Tal vez tienen hambre o sed, llévales un poco de agua y comida», le digo, intentando sonreír. Él obedece. Deja la recámara sin mirar atrás; lleva consigo la mochila, el libro y en la mano derecha un calcetín. iHa dejado a la abuela sin un calcetín! Ella ni lo notó. Intento verla una vez más. Tengo miedo de despertarla, la necesidad de guardar un recuerdo preciso de su cara es más fuerte que mi voluntad para dejarla dormir. Me acerco a la cama con cuidado. La llamo por su nombre, no contesta. «Teresa, ¿estás despierta todavía?». La miro cubierta y la quiero abrazar.

Emmanuel me grita desde el patio. Su voz todavía es muy aguda, pero pronto será tan grave como la mía. Noto su angustia. «iTío, los pájaros se han ido! iAbrí las jaulas para sacar los trastes de la comida y olvidé cerrarlas!», lo dice tan rápido que apenas logro entenderle. Levanto la cobija, la cara de la abuela tiene un gesto de total tranquilidad. Acerco mi mano a su mejilla para acariciarla. Teresa no reacciona, ya no se mueve. Entiendo todo. Por fin descansa. Entre los brazos tiene la fotografía que tanto quería. Ese bebé era Emmanuel, pienso. «La abuela también se fue, probablemente se llevó sus aves», respondo casi sin voz. Miro la herida que Teresa me ha dejado en el brazo, espero que nunca se borre.

IsRael Nicasio Álvarez. Profesor de asignatura de la Licenciatura en Enseñanza de Lenguas en la Universidad Autónoma de Tlaxcala (UATx), México, Unidad Académica Multidisciplinaria Campus Calpulalpan, y en la Secundaria 291 Ing. Javier Barros Sierra, en la Ciudad de México. Autor de los cuentos "Jugar a las canicas" y "Cajones vacíos", publicados por la Universidad Autónoma del Estado de México (UAEM), México. 